\title{
GROWTH, BREEDING, AND
}

RECRUITMENT IN SCOPIMERA

GLOBOSA AND ILYOPLAX PUSILLUS

(CRUSTACEA : OCYPODIDAE) IN

THE ESTUARY OF WAKA RIVER,

MIDDLE JAPAN

\section{$\operatorname{AUTHOR}(S):$}

Wada, Keiji

\section{CITATION:}

Wada, Keiji. GROWTH, BREEDING, AND RECRUITMENT IN SCOPIMERA GLOBOSA AND ILYOPLAXPUSILLUS (CRUSTACEA : OCYPODIDAE) IN THE ESTUARY OF WAKA RIVER, MIDDLE JAPAN. PUBLICATIONS OF THE SETO MARINE BIOLOGICAL LABORATORY 1981, 26(1-3): 243-259

\section{ISSUE DATE:}

1981-03-30

URL:

http://hdl.handle.net/2433/176012

RIGHT: 


\title{
GROWTH, BREEDING, AND RECRUITMENT IN SCOPIMERA GLOBOSA AND ILYOPLAX PUSILLUS (CRUSTACEA: OCYPODIDAE) IN THE ESTUARY OF WAKA RIVER, MIDDLE JAPAN ${ }^{1)}$
}

\author{
KEIJI WADA \\ Seto Marine Biological Laboratory, Kyoto University
}

With Text-figures $1-12$ and Table 1

\begin{abstract}
Field studies were conducted on the growth, breeding cycle and recruitment of the two ocypodid crabs Scopimera globosa De Haan and Ilyoplax pusillus De Haan, in the estuary of Waka River $\left(34^{\circ} 10^{\prime} \mathrm{N} 135^{\circ} 10^{\prime} \mathrm{E}\right)$. The sexual behaviors were observed from April through August in $S$. globosa and from May through August in I. pusillus. The ovigerous females of $S$. globosa were found from April through August and those of I. pusillus from May through September, being most abundant in June in both species. The newly settled juveniles were most abundant in August in both species, showing the occurrence of the most intensive settlement from July to August. The recruitment sites almost coincided with the adult habitat in both species. In I. pusillus the recruitment intensity was relatively higher at the area of higher adult density. But in S. globosa, it was higher at the area of lower silt-clay content in the bottom surface sediment in comparison with the area of higher silt-clay content, while the density of the larger adults tended to be relatively higher at the latter area, which indicates the shift of the main habitat in relation to the substratum with growth. The females of both species and the males of $S$. globosa commenced to breed in the second summer of their life, but many of the males of $I$. pusillus were suspected to breed in the third summer for the first time. It appeared that 1 . pusillus and the males of $S$. globosa overwintered two times at least after settlement, whereas in the females of $S$. globosa the overwintering in their second year was doubtful. These specific differences suggest that $S$. globosa has a slightly shorter longevity and a slightly earlier maturation than I. pusillus.
\end{abstract}

\section{Introduction}

Scopimera globosa De Haan and Ilyoplax pusillus De Haan are the intertidal crabs belonging to subfamily Scopimerinae of family Ocypodidae. They are small-sized species, the larger adults being around $10 \mathrm{~mm}$ in carapace breadth. Though both

1) Contributions from the Seto Marine Biological Laboratory, No. 674.

Publ. Seto Mar. Biol. Lab., XXVI (1/3), 243-259, 1981 . (Article 13) 
species occur commonly on the tidal flats of bays, inlets and estuaries in central and western Japan, $S$. globosa is distributed wide from Hokkaido to Okinawa in Japan and also in Korea, North China and Formosa (Sakai, 1976), whereas I. pusillus is known from the northern Honshu to Okinawa and in Korea (Ono, 1963; Wada and Tsuchiya, 1975; Sakai, 1976; Nakasone, 1977).

The modes of life of the two species are more or less similar. Both species dig an almost vertical unbranched burrow, which scarcely exceeds $15 \mathrm{~cm}$ in depth. They hide in the burrow when the surface is submersed under water, and emerge when it is exposed to air but seldom at night. In the early period of their daytime emergence, they chiefly devote themselves to feeding in the vicinity of their burrows, but later the proportion of the males increases, that perform the rhythmic motion of the chelipeds, waving or beckoning, particularly in the breeding season. In the cold season from December to March, both species are dormant burried in the substratum, except for the warm and calm days.

Although the two species inhabit the same higher zone of the intertidal flat each other, they show marked difference in the substratum preference; $S$. globosa prefers coarse sand and I. pusillus mud and muddy sand, as has been so far pointed out by the grain size distribution of the surface sand (Ono, 1959, 1962: Wada and Tsuchiya, 1975; Wada, 1976). In addition, there have been many works describing the distribution in relation to the substratum also in other ocypodid species, recently by Hartnoll (1973), Frith and Frith (1977), Icely and Jones (1978), and Frith and Brunenmeister (1980), for example. It has not been, however, investigated whether the substratum preference is different or not in the crab size of the same species, not only in $S$. globosa and $I$. pusillus but also in other ocypodids.

Many ecological studies have been conducted on S. globosa or I. pusillus, that deal with the interactions among individuals (Harada and Kawanabe, 1955; Ono, 1957, 1960, 1965; Sugiyama, 1961; Yamaguchi et al., 1978), the distribution (Ono, 1959, 1962, 1965; Wada and Tsuchiya, 1975; Wada, 1976), the characteristics of the burrows (Utashiro and Horii, 1965), and the sexual behaviors (Yamaguchi et al., 1979); but only the work by Yamaguchi and Tanaka (1974) on S. globosa in Amakusa, Kyushu is concerned with life cycles.

There are two objectives in the present study. One is to describe the breeding and recruitment periods and the growth of both species at some areas differing in the substratum in the estuary of Waka River $\left(34^{\circ} 10^{\prime} \mathrm{N} 135^{\circ} 10^{\prime} \mathrm{E}\right)$ and to compare them between these two ocypodid crabs. And another is to know whether the distribution in relation to the substratum is different or not in the crab size, particularly between the adults and the newly settled juveniles in each of the two species.

\section{Methods}

\section{Survey through Collecting}

Six sampling sites were selected in the intertidal flats of the estuary of Waka River, three (Sts. 1, 3 and 5) populated by S. globosa, one (St. 6) by $I$. pusillus, and 


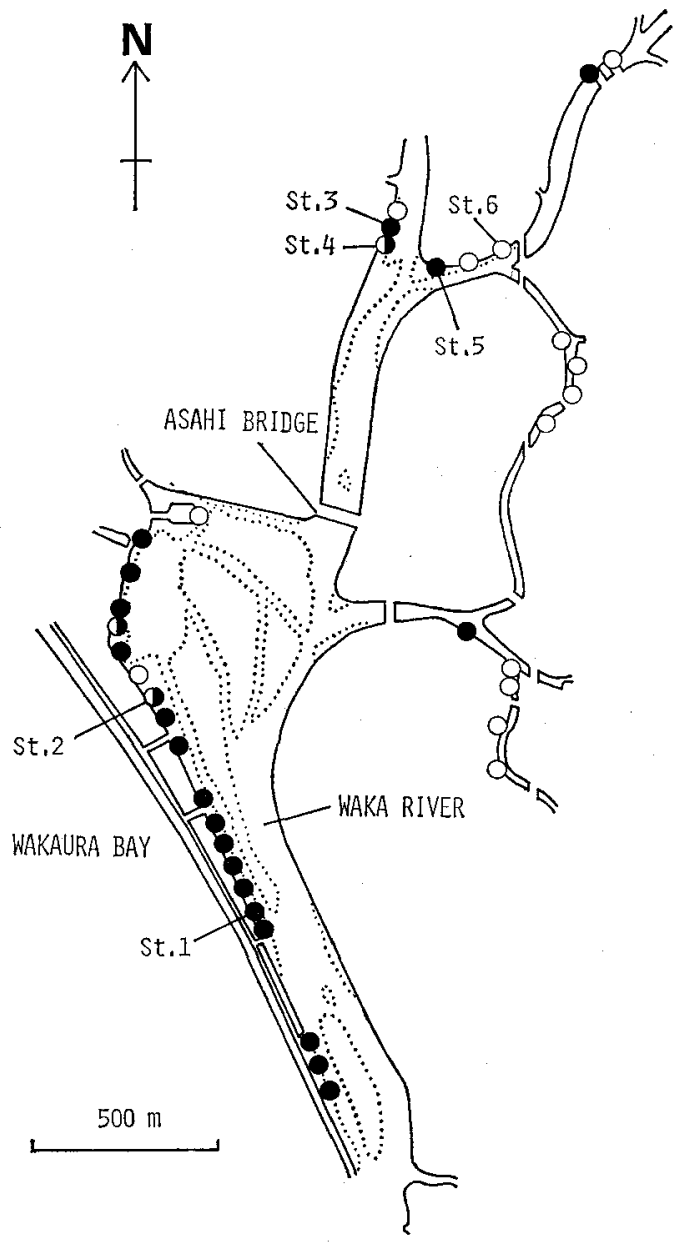

Fig. 1. The map of Waka River and its tributaries showing the areas occupied by Scopimera globosa (solid circles), by Ilyoplax pusillus (open circles) and by both species (half-solid/open circles), and the sampling stations. The dotted line indicates the outline of the tidal flat at low tide. The distribution of the two species is shown on the tidal flats connected with the bank, but not on the flats surrounded by tidal creek.

two (Sts. 2 and 4 ) by both species (Fig. 1). Samples of both species were collected periodically between July 1976 and July 1977 at the daytime low tide around spring tides. Four quadrats of $25 \mathrm{~cm} \times 25 \mathrm{~cm}$ were set at each station in the area where the density of burrows was apparently higher, and the substrates within them were dug up by a scoop, to a depth of $20 \mathrm{~cm}$ to capture the crabs. From April to July of 1977, when a male and a female were found together in one burrow, such pairs were kept separated from others.

The crabs were fixed in $10 \%$ formalin. Carapace breadth was measured to the nearest $0.1 \mathrm{~mm}$ with a micrometer under a binocular microscope, and the sex of each individual and the reproductive condition of each female were noted. In $S$. 
globosa, carapace breadth was measured between the incisions of the anterolateral margins, which is not the widest part of the carapace, whereas in $I$. pusillus the widest part was measured.

Substrate samples were collected from the upper 2-3 mm layer and the lower $10-15 \mathrm{~cm}$ layer at each station in July 1976 and July 1977. Samples were dried at $100^{\circ} \mathrm{C}$ for $5-10$ hours and then sieved with the standard sieve and weighed for each fraction.

\section{Burrow Census}

In 1973, the burrow density was surveyed at 18 stations populated by $S$. globosa in July and at 8 stations by $I$. pusillus in October. At each station, 3 to 5 quadrats of $50 \mathrm{~cm} \times 50 \mathrm{~cm}$ were randomly set to count the number of burrows separately for the large ones $(5 \mathrm{~mm}$ or more in diameter) and the small ones (less than $5 \mathrm{~mm}$ ). In the census for $S$. globosa in July, the upper 1-2 cm substrate was sampled to be analysed for particle size distribution at each of the 17 stations.

The small burrows of $S$. globosa, with sand piled high above the entrances, which were characteristic of the burrows of the newly settled juveniles and will be called, for convenience, the hooded burrows, were intensively observed and recorded of their occurrence monthly from May through October in each year of 1974 to 1977 . Especially, in July, August, and September of 1977, the densities of the hooded burrows as well as the other burrows were surveyed at 7-11 stations randomly setting 3 to 5 quadrats of $50 \mathrm{~cm} \times 50 \mathrm{~cm}$ at each station.

\section{Observations of the Sexual Behavior}

Whenever the copulation or other sexual behaviors were witnessed, the details of the couple and the surrounding condition were recorded and some pairs were captured to take measurement. Observations were made in the non-dormant period from April to December from 1974 to 1977.

\section{Results}

\section{Habitat Conditions}

All sampling stations were situated at the similar level of the tidal flat near the base of the embankment, nearly around mean tidal level (109 $\mathrm{cm}$ above datum) (Table 1).

The granularity of the substratum at each station is shown in Table 1. At each station there was not so much difference in granularity between 1976 and 1977, though silt-clay percentage was slightly higher in 1977 than in 1976 at all stations except St. 2. Among all the stations, the silt-clay content was lowest at St. 1 in both the surface and the deeper layer, whereas it was highest at St. 6 in the surface layer and at St. 4 in the deeper one, respectively. And the silt-clay content of the surface layer increased in the order from Sts. 1, 5, 2, 3, 4 to 6 successively. It is evident that the silt-clay content was lower at the stations populated by $S$. globosa than those by $I$. 
Table 1. Silt-clay percentage, median diameter $\left(\mathbf{M}_{d \phi}\right)$, mean diameter $\left(\mathbf{M}_{\phi}\right)$, sorting $\left(\boldsymbol{\sigma}_{\phi}\right)$ and skewness $\left(\alpha_{\phi}\right)$ of the upper 2-3 mm layer (a) and the lower 10-15 cm layer (b) at each station. Each index of the granularity was calculated according to Mogi (1971).

\begin{tabular}{|c|c|c|c|c|c|c|c|c|c|c|c|c|}
\hline & & \multicolumn{5}{|c|}{ Jul. 1976} & \multicolumn{5}{|c|}{ Jul. 1977} & \multirow{2}{*}{$\begin{array}{l}\text { Height } \\
\text { above } \\
\text { datum } \\
(\mathrm{cm})\end{array}$} \\
\hline & & $\begin{array}{c}\text { silt-clay } \\
\%\end{array}$ & $\mathbf{M}_{d \boldsymbol{\phi}}$ & $\mathrm{M}_{\phi}$ & $\sigma_{\phi}$ & $\alpha_{\phi}$ & $\begin{array}{c}\text { silt-clay } \\
\%\end{array}$ & $\mathrm{M}_{d \phi}$ & $\mathrm{M}_{\phi}$ & $\sigma_{\phi}$ & $\alpha_{\phi}$ & \\
\hline \multirow{2}{*}{ St. 1} & a & 0.15 & 1.47 & 1.49 & 0.51 & 0.04 & 0.91 & 1.68 & 1.67 & 0.47 & -0.02 & \multirow{2}{*}{106} \\
\hline & b & 0 & 1.50 & 1.50 & 0.52 & 0 & 0 & 1.68 & 1.67 & 0.53 & -0.02 & \\
\hline \multirow{2}{*}{ St. 2} & a & 2.60 & 2.06 & 2.08 & 0.68 & 0.02 & 2.29 & 2.08 & 2.05 & 0.64 & -0.02 & \multirow{2}{*}{105} \\
\hline & $\mathrm{b}$ & 2.50 & 2.07 & 2.05 & 0.65 & -0.03 & 2.00 & 2.05 & 2.04 & 0.64 & -0.02 & \\
\hline \multirow{2}{*}{ St. 3} & a & 3.01 & 1.80 & 1.79 & 0.86 & -0.01 & 3.21 & 1.66 & 1.58 & 0.93 & -0.09 & \multirow{2}{*}{113} \\
\hline & $b$ & 1.57 & 1.75 & 1.74 & 0.94 & -0.02 & 4.44 & 1.80 & 1.94 & 0.86 & 0.16 & \\
\hline \multirow{2}{*}{ St. 4} & a & 4.56 & 1.72 & 1.76 & 0.94 & 0.04 & 5.09 & 1.60 & 1.73 & 1.03 & 0.12 & \multirow{2}{*}{109} \\
\hline & $\mathrm{b}$ & 5.48 & 1.75 & 1.80 & 1.00 & 0.05 & 6.20 & 1.80 & 1.98 & 0.92 & 0.20 & \\
\hline \multirow{2}{*}{ St. 5} & a & 1.64 & 1.75 & 1.79 & 0.61 & 0.07 & 2.19 & 1.60 & 1.73 & 0.66 & 0.19 & \multirow{2}{*}{107} \\
\hline & $\mathrm{b}$ & 1.68 & 1.70 & 1.75 & 0.65 & 0.08 & 1.68 & 1.65 & 1.76 & 0.58 & 0.18 & \\
\hline \multirow{2}{*}{ St. 6} & a & 5.00 & 1.88 & 1.93 & 0.78 & 0.06 & 6.97 & 1.85 & 1.95 & 0.85 & 0.12 & \multirow{2}{*}{113} \\
\hline & b & 3.84 & 1.83 & 1.90 & 0.70 & 0.10 & 5.98 & 1.80 & 1.93 & 0.88 & 0.14 & \\
\hline
\end{tabular}
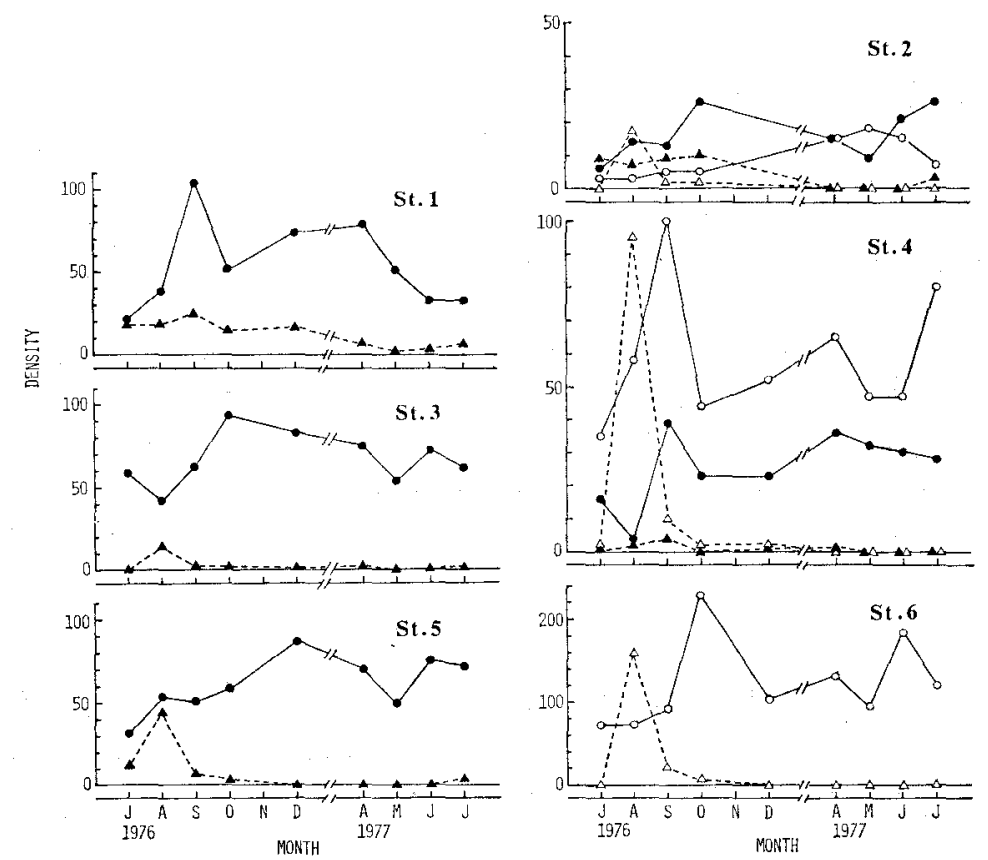

Fig. 2. Scopimera globosa and Ilyoplax pusillus. Fluctuations in the number of individuals collected per $0.25 \mathrm{~m}^{2}$ at each station from July 1976 to July 1977 . The solid circles and triangles indicate sexable and unsexable $S$. globosa, respectively, and the open circles and triangles sexable and unsexable $I$. pusillus, respectively. 
pusillus, in general.

\section{Density and Size Structure}

Fig. 2 shows the number of crabs collected from four $25 \mathrm{~cm} \times 25 \mathrm{~cm}$ quadrats at each station. In both $S$. globosa and $I$. pusillus, the unsexable crabs smaller than 2.5 $\mathrm{mm}$ in carapace breadth were abundant from July through September or October, with their main peaks in August. The maximum density of the unsexable crabs was much higher in $I$. pusillus $\left(158 / 0.25 \mathrm{~m}^{2}\right)$ than in $S$. globosa $\left(44 / 0.25 \mathrm{~m}^{2}\right)$.

The density of the sexable crabs also showed the seasonal fluctuation in both species, with more or less marked increase in summer through autumn and decrease in spring. The maximum density of the sexable crabs was higher in $I$. pusillus $\left(231 / 0.25 \mathrm{~m}^{2}\right)$ than in $S$. globosa $\left(104 / 0.25 \mathrm{~m}^{2}\right)$.

Among the three stations (Sts. 1, 3 and 5) populated solely by $S$. globosa, the density of the unsexable crabs was highest at St. 1 and lowest at St. 3 in almost all months. In sexable $S$. globosa, there was not so much difference in their density among the three stations except the summer months, in which it was lower at St. 1 than at Sts. 3 and 5. From the size-frequency distributions at these three stations (Fig. 3), it could be recognized that the large sexable crabs of 6.0-9.5 mm exhibited the lower densities at St. 1 than at Sts. 3 and 5 on the whole, particularly in October and December.

At the two stations (Sts. 2 and 4) populated by both species, the density of $S$.

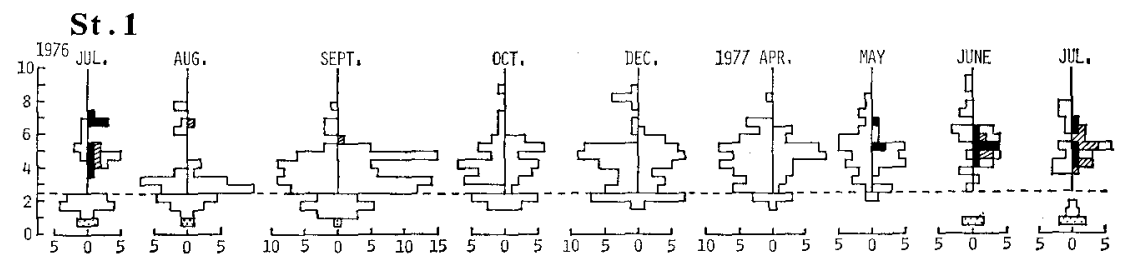

St. 3

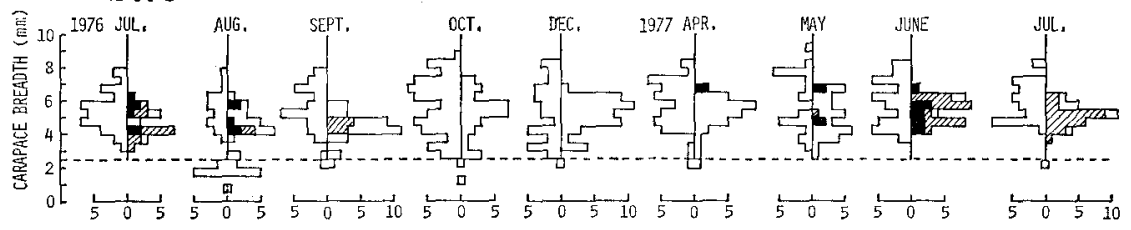

St. 5

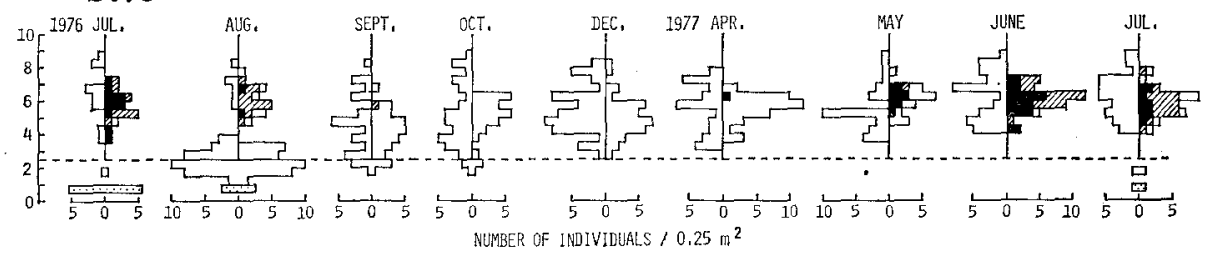

Fig. 3. Scopimera globosa. Size-frequency distributions from Sts. 1, 3 and 5 populated solely by S. globosa from July 1976 to July 1977. Sexable specimens are separated in males (left) and females (right). The ovigerous and the spent females, and the megalopac are shown by the solid, the hatched, and the dotted histograms, respectively. 


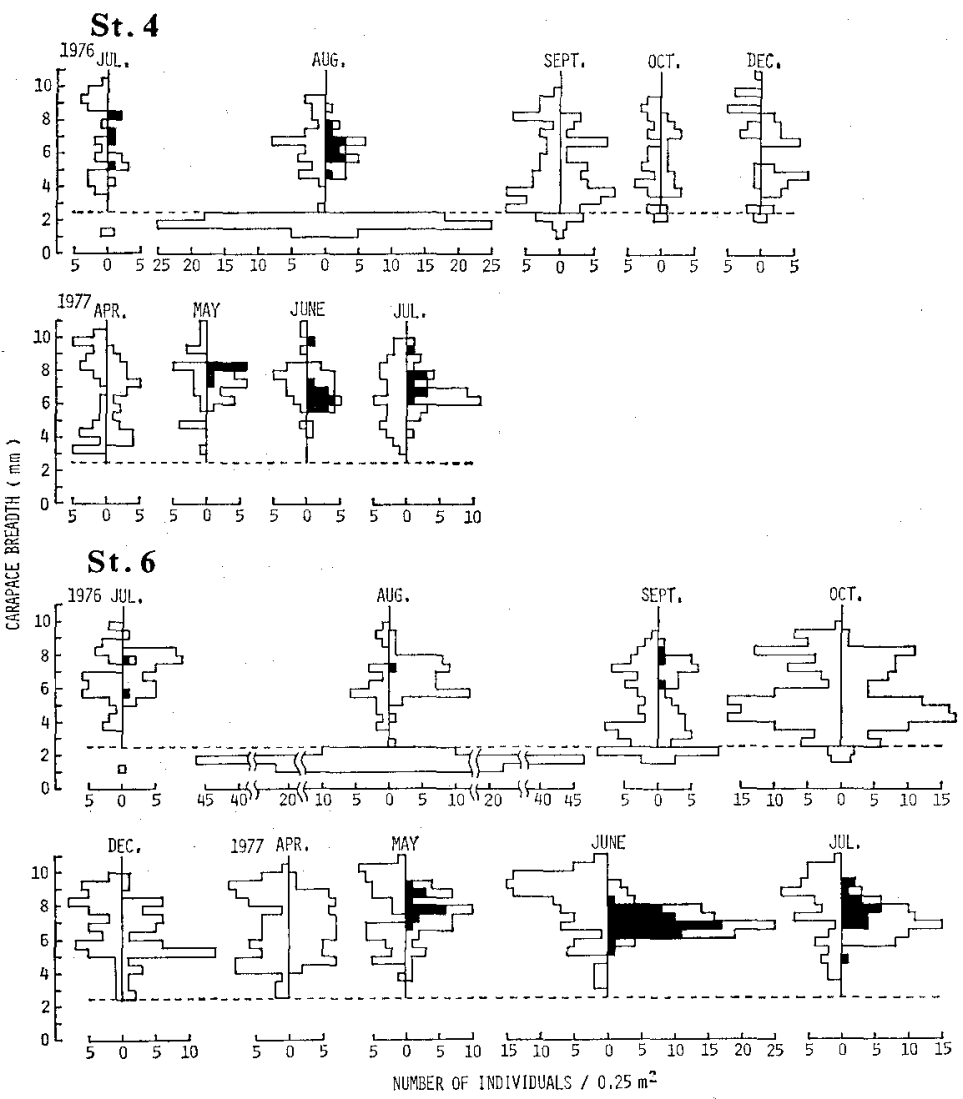

Fig. 4. Ilyoblax pusillus. Size-frequency distributions from Sts. 4 and 6 from July 1976 to July 1977. Sexable specimens are separated in males (left) and females (right). The solid histograms indicate the ovigerous females.

globosa was lower than at Sts. 1, 3 and 5 except for the unsexable crabs at St. 2 which generally showed the higher density than those at St. 3. And between Sts. 2 and 4, the density of unsexable $S$. globosa was higher at St. 2 than at St. 4, while in sexable $S$. globosa the reverse was true.

In I. pusillus, the density was highest at St. 6 and lowest at St. 2 in both unsexable and sexable crabs. Fig. 4 shows the size-frequency distributions of I. pusillus at Sts. 4 and 6 , from which the marked difference could not be recognized between the two stations.

\section{Growth}

Growth after settlement will be considered from the size-frequency distributions obtained at sampling stations for successive months (Figs. 3-6).

\section{(1) Scopimera globosa}

Juveniles

The early juveniles of $1.5-2.5 \mathrm{~mm}$ in carapace breadth appeared in July. These 


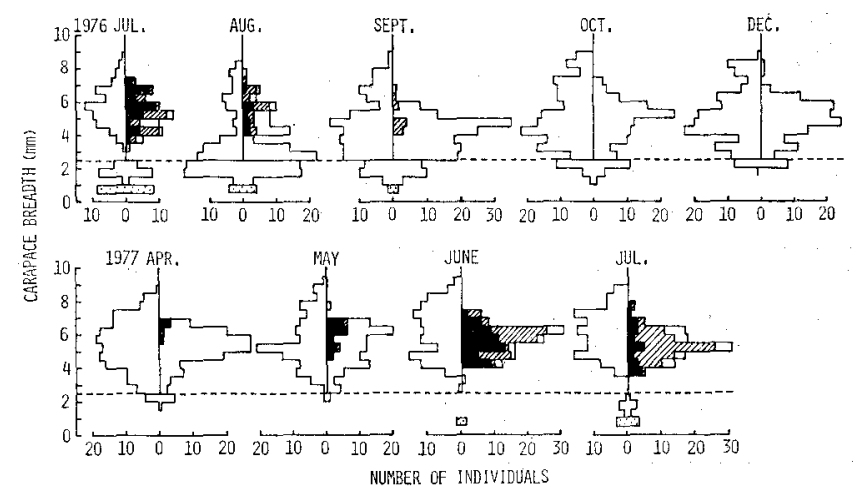

Fig. 5. Scopimera globosa. Size-frequency distributions from Sts. 1, 2, 3, 4 and 5 combined from July 1976 to July 1977 . Histograms plotted in the same way as those of Fig. 3.

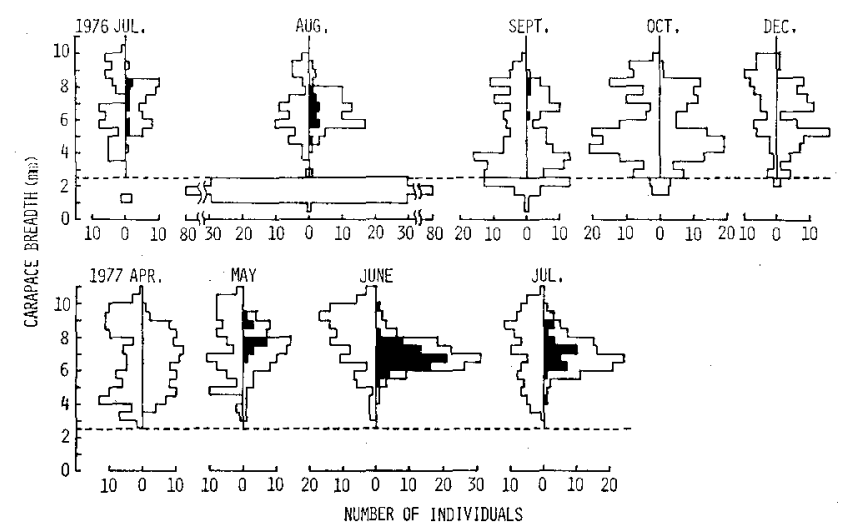

Fig. 6. Ilyoplax pusillus. Size-frequency distributions from Sts. 2, 4 and 6 combined from July 1976 to July 1977. Histograms plotted in the same way as those of Fig. 4.

juveniles occurred until May of the following spring, with their size modes changing from $1.5-2.0 \mathrm{~mm}$ in summer to $2.0-2.5 \mathrm{~mm}$ after autumn.

Males

Young males first appeared in August, which measured about $3 \mathrm{~mm}$ in carapace breadth. The major component of the males continued to grow and exhibited a peak of carapace breadth at $4.0-5.0 \mathrm{~mm}$ in December. Another less conspicuous size modes of young males were also sometimes noticeable at smaller sizes. These males merged with the large groups and the size modes became obscure in April to July, thus growth of them was difficult to follow afterwards. However, most of the large groups of $4.0-8.0 \mathrm{~mm}$ in August could be regarded to be in the second year of their life, and they continued to grow and reached $7.0-9.0 \mathrm{~mm}$ in the following December. It was probable that these groups overwintered again, which was supposed from the presence of the males larger than $8 \mathrm{~mm}$ in April and May at Sts. 1 and 3. 

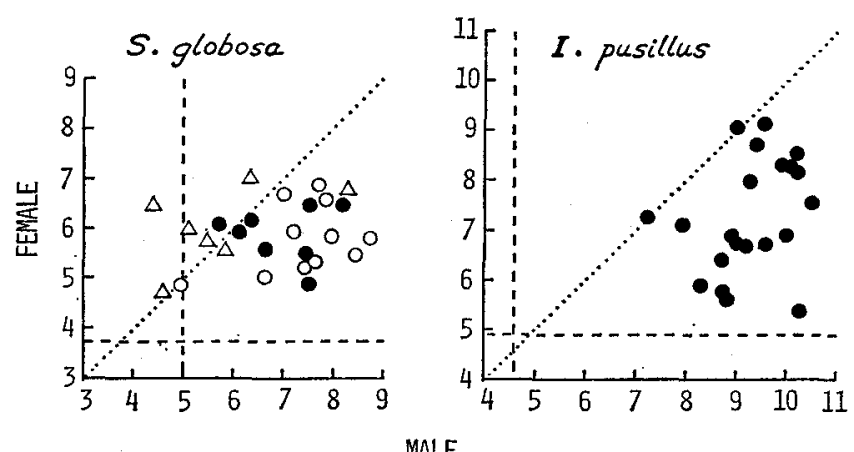

Fig. 7. Scopimera globosa and Ilyoplax pusillus. The sizes (carapace breadth) of the pairing male and female. The solid circle indicates the pair which were found being together in one burrow. The broken lines represent the minumum sizes of the waving males and of the ovigerous females in each species. The open circle and the triangle in S. globosa show the pairs which were observed to perform the sexual behavior of Type 1 and that of Type 2, respectively.

Since the minimum sizes of the males which were observed to copulate or to perform the waving display were $4.4 \mathrm{~mm}$ and $5.0 \mathrm{~mm}$ in carapace breadth, respectively (Fig. 7), it is certain that males commence to wave and become mature in the second summer of their life.

\section{Females}

Females followed the similar pattern of growth to males. Young females first occurred in August, their carapace breadths ranging from 2.5 to $4.0 \mathrm{~mm}$. The population peaks in carapace breadth were more or less similar to those of males through autumn and winter until April. During April to July, the size modes were kept rather defined throughout and reached 5.0 to $6.0 \mathrm{~mm}$. The groups larger than 4 $\mathrm{mm}$ in August could be regarded to be in the second year of their life, but after September they merged with the young groups and could not be traced.

From the sizes of the ovigerous females, it is certain that they mature and bear eggs in the second summer of their life.

\section{(2) Ilyoplax pusillus}

\section{Juveniles}

The early small juveniles appeared in July, their size being from 1.0 to $1.5 \mathrm{~mm}$ in carapace breadth. These juveniles occurred until December, but their size modes were in 1.5 to $2.0 \mathrm{~mm}$ in August and in 2.0 to $2.5 \mathrm{~mm}$ after September.

Males

Young males first appeared in very few numbers in August, which measured about $3 \mathrm{~mm}$ in carapace breadth. The major component of these males continued to grow, with their peaks changing from $3.5-4.0 \mathrm{~mm}$ in September to $5.0-6.0 \mathrm{~mm}$ in December. These males merged with the large groups and the size modes became obscure in April to July, thus their growth was difficult to follow afterwards. Most of the males larger than $3.5 \mathrm{~mm}$ in August were regarded to be in the second year 
of their life. The presence of these old groups was recognizable through autumn and winter until May, their sizes reaching 8.0 to $11.0 \mathrm{~mm}$ in April or May. It is, therefore, certain that males overwinter two times at least after settlement.

The males which were observed to mate were limited to the larger ones and even the smallest measured $7.2 \mathrm{~mm}$ (Fig. 7), thus many of males may commence to breed in the third summer of their life and not in the second summer yet except the larger ones. Contrary, they are certain to commence to perform the waving display in their second summer, since the smallest male which was observed to wave measured $4.6 \mathrm{~mm}$ (Fig. 7).

Females

Females followed the similar pattern of growth to males. Young females first appeared in very few numbers in August, which measured about $3 \mathrm{~mm}$ in carapace breadth. The population peaks of these young groups in carapace breadth were more or less similar to those of young males through autumn to winter, but after April they merged with the large groups as seen in males. Most of the females larger than $4 \mathrm{~mm}$ in August were regarded to be in the second year of their life and their presence was recognizable until December, their size reaching 6.5 to $10.0 \mathrm{~mm}$. After April their size modes were obscured, but the presence of the females larger than $8 \mathrm{~mm}$ in April indicated their second overwintering.

From the size of the ovigerous females it is certain that they mature and bear eggs in the second summer of their life. It is probable that they also bear eggs after their second overwintering, which was supposed from the presence of the ovigerous females larger than $8.5 \mathrm{~mm}$ in May and June.

\section{Sexual Behavior}

\section{(1) Scopimera globosa}

As has been reported by Yamaguchi et al. (1979), two types of the sexual behavior were recognized for this species also in Waka River.

Type 1: A male chases a female and at the moment he captures her, they complete copulation on the substrate surface.

Type 2: Copulation is not performed on the surface. After capturing a female on the surface, the male carries her to his burrow and pushes her down into it. He follows her into the burrow, and after a short while he plugs the burrow by scraping up the sand from around the entrance or from inside the burrow.

Fig. 7 illustrates the sizes of the male and the female of each pair, which were observed to perform the sexual behavior of each type or to dwell together in a burrow. The minimum size of the pairing males was almost the same as that of the waving males, which indicates that the waving display is characteristic of the mature male. Likewise, the minimum size of the pairing females was similar to that of the ovigerous females. The males engaged in Type 2 were never smaller than the females, while in some pairs engaged in Type 1 the males were smaller than the females, and such size difference of the crabs between the two types was also recognized in Amakusa, Kyushu (Yamaguchi et al., 1979). 


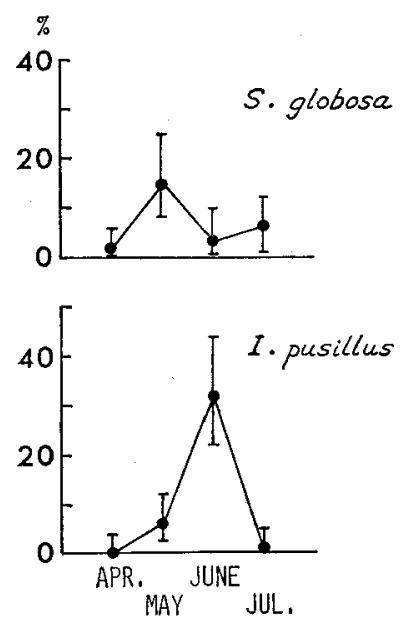

Fig. 8. Scopimera globosa and Ilyoplax pusillus. The monthly fluctuations in the proportion of the number of pairs, each one of which occupied one burrow, to the number of the mature females with the bar of $90 \%$ confidence limit.

During the period of May 1974 to July 1978, both types of the sexual behavior were observed in every month from April through August, but in other months neither of them was encountered in Waka River. From the monthly samples from April through July in 1977, the proportion of the number of pairs, each one of which occupied one burrow, to the number of females larger than the smallest ovigerous female was calculated and shown in Fig. 8. From this it was suggested that the sexual behavior of Type 2 had been performed more frequently in May than in other three months in this species.

(2) Ilyoplax pusillus

Copulation had never been observed on the surface in this species. When a wandering female passes near a waving male, he directs his wave intensively toward her. If she approaches him, he waves more violently to her. When she comes up close to his burrow, he suddenly enters the burrow, and subsequently she follows him in. After a while, the male emerges from the burrow and plugs it up by scraping up the sand from around its entrance to hide underground. In case when the female does not approach the male in disregard of his violent waving, the male is sometimes observed circling around her with his both chelipeds held up or rushing to her to force her to enter his burrow. I once encountered a copulating pair in a burrow on digging the substrate, and it may be safely said that the copulation is performed underground after such successive behaviors.

Fig. 7 illustrates the sizes of the male and the female of each pair which occupied one burrow together. There was no pair in which the female was larger than the male. The minimum size of the pairing females was almost the same as that of the ovigerous females. The smallest pairing male was much larger than the smallest waving male, which suggests that the waving display is possibly performed 
by the immature males as well.

During 1974 through 1978, the sexual behaviors were observed from May through August and not in other months. From the monthly samples from April to July in 1977, the proportion of the number of pairs, each one of which occupied one burrow, to the number of females larger than the smallest ovigerous female was calculated as in S. globosa (Fig. 8), from which it was suggested that the frequency of the sexual behavior was by far higher in June than in other three months.

\section{Ovigerous and Spent Females}

The smallest ovigerous female was $3.75 \mathrm{~mm}$ in $S$. globosa and $4.9 \mathrm{~mm}$ in $I$. pusillus in carapace breadth.

Frequency of the ovigerous and the spent females at sampling stations are shown in the size-frequency distributions for successive months (Figs. 3-6). In S. globosa, ovigerous females were collected from April through August at Sts. 3 and 5 and from May through July at St. 1, with the peak in June at all the three stations, and spent females were seen from May or from June through September, with increased numbers in the period of June to August. Ovigerous females of $I$. pusillus, on the other hand, were collected from May through August or through September and were commonest in June. As for the spent females of $I$. pusillus, the period of their occurrence was unknown. The ovigerous females of both species were recognized to be larger in the early breeding season of April or May.

\section{Recruitment Periods}

\section{(1) Scopimera globosa}

The earliest record of the occurrence of hooded burrows constructed by the newly settled juveniles was in June or July in each year. It seemed, however, that the recruitment did not always begin at the same time in the whole estuary as follows. In June of 1977, the hooded burrows were not found anywhere in the upstream area above Asahi Bridge, though a few were already recognized in the downstream area. Similar tendency was indicated also in the result that in June of 1977 the megalopae were collected at St. 1 of the downstream area but not yet at Sts. 3 and 5 of the upstream one (Fig. 3). In July, too, the density of the hooded burrows was lower in the upstream area than in the downstream one, but in August and September it was not so different between them (Fig. 9). It is certain that the settlement lasts till September at least because the megalopae were collected until September (Figs. 3 and 5).

According to the burrow census from July to September, the density of the hooded burrows at each station was highest in August among the three months (Fig. 9). Moreover, as read from Fig. 2, the density of the unsexable juveniles was highest in August among all of the months surveyed at Sts. 3 and 5, though it was almost the same from July through October at Sts. 1 and 2. These facts indicate that the settlement occurs most intensively from July to August in most areas of the estuary. 


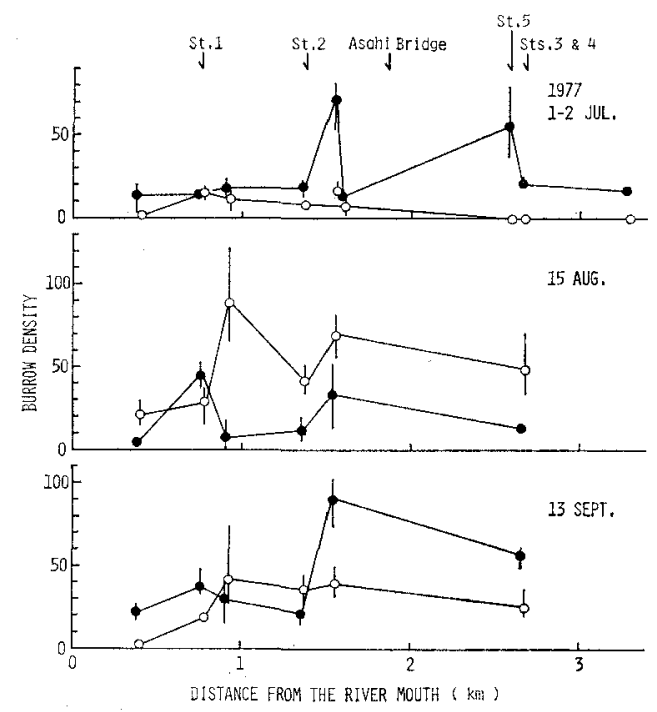

Fig. 9. Scopimera globosa. Mean densities of the hooded burrows (open circles) and the other ones (solir circles) per $0.25 \mathrm{~m}^{2}$ with the bar showing the range of density in relation to the distance from the river mouth from July through September, 1977.

\section{(2) Ilyoplax pusillus}

Since the megalopae of this species could not be collected at each of the sampling stations, the period of the settlement could not be determined. But it was evident that the unsexable juveniles appeared from July through October or through December and their density was by far highest in August among all of the months surveyed (Fig. 2), which suggests that the settlement begins in June or July and occurs most intensively from July to August.

\section{Recruitment Sites}

\section{(1) Scopimera globosa}

From Fig. 9 it can be said that the hooded burrows of the newly settled juveniles occurred in the area inhabited by adults. During this burrow census, no hooded burrows were found in the lower level as well as in the muddy area where I. pusillus or Macrophthalmus japonicus occurred. Thus the recruitment site seemingly coincided with the adult habitat. But from the burrow counting in July 1973, the recruitment intensity could not be regarded to be correlated with the adult density (Fig. 10).

Fig. 11 shows the burrow density in relation to the silt-clay percentage of the substratum and the intertidal height. Against the both factors the recruitment range was almost the same as the range of adult distribution and any noticeable peak of the recruitment intensity was not recognizable. But as with the silt-clay percentage, the recruitment showed the relatively lower intensity at the range above $1 \%$, although in the adult burrows the similar density remained all over the range. 


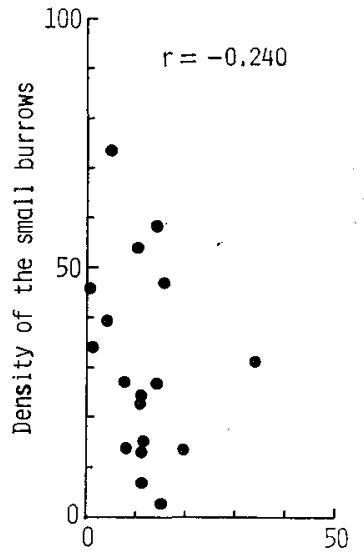

Density of the large burrows

Fig. 10. Scopimera globosa. Relation between the mean densities of the large burrows $(5 \mathrm{~mm}$ or more in diameter) and of the small ones (less than $5 \mathrm{~mm}$ ) per $0.25 \mathrm{~m}^{2}$ at each station from the census in July of 1973.

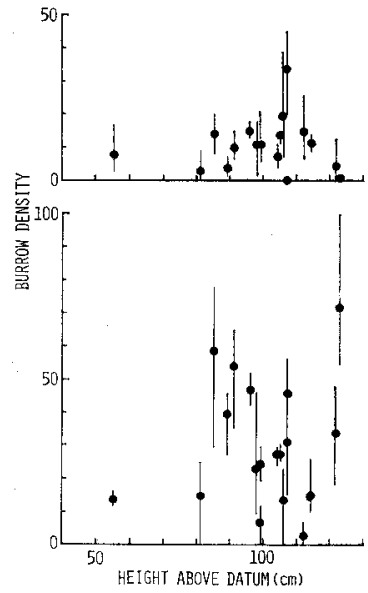

Fig. 11. Scopimera globosa. Mean densities of the large burrows (upper) and of the small ones (lower) per $0.25 \mathrm{~m}^{2}$ with the bars showing the range of density in relation to the silt-clay percentage of the substratum and the intertidal height from the census in July of 1973.

Similar tendency was also recognized from Fig. 2 as follows. Among the stations inhabited by this species, the density of the unsexable juveniles was relatively lower at St. 3 or St. 4 where the surface sand had the rather higher content of silt-clay (Table 1), though the density of the sexable crabs was not so much lower in comparison with other stations.

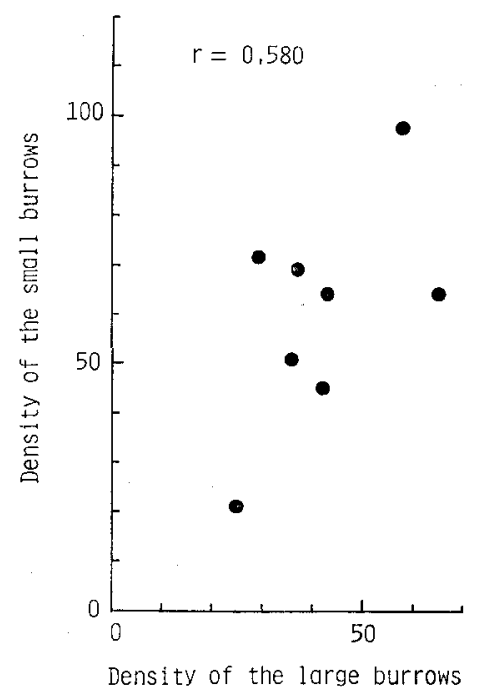

Fig. 12. Ilyoplax pusillus. Relation between the mean densities of the large burrows ( $5 \mathrm{~mm}$ or more in diameter) and of the small ones (less than $5 \mathrm{~mm}$ ) per $0.25 \mathrm{~m}^{2}$ at each station from the census in October of 1973. 


\section{(2) Ilyoplax pusillus}

The juveniles of this species were observed in the area inhabited by adults, but they were never found in the muddy and low level area occupied by Macrophthalmus japonicus, nor in the sandy area devoid of $I$. pusillus. Hence the recruitment site seemingly coincided with the adult habitat as in $S$. globosa. And according to the result of the burrow counting, the recruitment intensity seemed to be correlated with the adult density (Fig. 12). Similar tendency was recognized also in the finding from Fig. 2, that among the three stations where 1 . pusillus occurred, the density of the unsexable juveniles was highest at St. 6 occupied by many sexable crabs and lowest at St. 2 almost lacking adults.

\section{Discussion and Conclusions}

\section{Relationships with Substratum Condition}

In each of $S$. globosa and $I$. pusillus, there has not been so much difference, on the whole, in the growth pattern as well as in the occurring period of the ovigerous females among stations, in disregard of the difference of the substratum condition. But the recruitment of the juveniles and the occurrence of the large adults were associated with the difference of the granularity of the substratum as follows.

In $S$. globosa, the recruitment sites coincided with the adult habitat in general, but in detail, its intensity was relatively higher at the area of lower silt-clay content in the bottom surface sediment and was lower at the area of higher silt-clay content in it. On the contrary, as with the adults, similar densities remained all over their distributional range in the silt-clay percentage. From the comparison of the size structure among Sts. 1, 3 and 5, however, it was recognized that the density of the larger adults was higher at Sts. 3 and 5 than at St. 1. In addition, by taking the fact into consideration that the silt-clay content was lower at. St. 1 than at Sts. 3 and 5, it follows that the larger adults are more abundant at the area of the relatively higher silt-clay content. Thus, it is indicated that the settlement occurs abundantly at the area of lower silt-clay content but as they grow larger, their main habitat is slightly shifted to the area of relatively higher silt-clay content.

In $I$. pusillus, on the other hand, the recruitment intensity was higher at the area inhabited by many adults and eventually the distribution of the juveniles in relation to the substratum was similar to that of the adults. This fact may have a conncetion with the dwelling of some of the juveniles in the adult burrows in this species.

From these findings in both species, it is considered that the habitat in relation to the substratum is segregated between $S$. globosa and $I$. pusillus to a little more extent at the juvenile stages than at the adult ones.

\section{Comparison of the Life Cycles}

In the estuary of Waka River, the sexual behavior of $S$. globosa was observed from April through August with the peak being in May while in I. pusillus it was 
from May through August and its peak in June. The ovigerous females appeared from April through August and the newly settled juveniles were first collected in June in S. globosa, whereas in I. pusillus from May through September and in July, respectively, though the peaks of the settlement were from July to August in both species. From the same estuary, the ovigerous females of $S$. globosa were captured also from April through early September in 1976 (Marumura, unpublished) and those of I. pusillus from May through September in 1978 (Kadono, unpublished), suggesting little yearly difference in the breeding period. Thus it follows that both breeding and settlement occur earlier by about a month in S. globosa than in I. pusillus in the estuary, though the length of the occurrence of the ovigerous females is about six months in both species.

It has been clarified that the females of both $S$. globosa and I. pusillus attain the adult size and commence to breed in the second summer of their life. But many of male $I$. pusillus were suspected to breed in the third summer whereas the males of $S$. globosa in the second summer as in the females. Besides it has been indicated that the males of $S$. globosa and both the males and females of $I$. pusillus overwinter two times at least after settlement but in the females of $S$. globosa the second overwintering is doubtful. From these facts, $S$. globosa is supposed to have a slightly shorter longevity and a slightly earlier maturation in their life than I. pusillus.

\section{Acknowledgements}

I am indebted to Prof. E. Harada of the Seto Marine Biological Laboratory of Kyoto University, and Prof. H. Kawanabe, Dr. M. Nishihira and Mr. A. Taki of the Laboratory of Animal Ecology, Department of Zoology, Kyoto University for their critical advices and reading the manuscript. I am also indebted to the members of the Seto Marine Biological Laboratory of Kyoto University for their many helpful discussions.

\section{REFERENCES}

Frith, D.W. and Brunenmeister, S. 1980. Ecological and population studies of fiddler crabs (Ocypodidae, genus $U_{c a}$ ) on a mangrove shore at Phuket Island, western peninsular Thailand. Crustaceana, Vol. 39 (2), pp. 157-184.

__ and Frith, G.B. 1977. Observations on fiddler crabs (Ocypodidae: genus Uca) on Surin Island, western Peninsular Thailand, with particular reference to Uca tetragonon (Herbst). Phuket Mar. Biol. Center Res. Bull., No. 18, pp. 1-14.

Harada, E. and Kawanabe, H. 1955. The behavior of the sand-crab, Scopimera globosa DE HAAN, with special reference to the problem of coation between individuals. Jap. J. Ecol., Vol. 4 (4), pp. 162-165. (in Japanese with English summary).

Hartnoll, R.G. 1973. Factors affecting the distribution and behaviour of the crab Dotilla fenestrata on East African shores. Estuarine and Coastal Marine Science, Vol. 1, pp. 137-152.

Icely, J.D. and Jones, D.A. 1978. Factors affecting the distribution of the genus Uca (Crustacea: Ocypodidae) on an East African shore. Ibid., Vol. 6, pp. 315-325.

Mogi, A. 1971. Shoreline and Breaker Zone, pp. 109-252. In: Geology of Sublittoral Zone. Ed. M. Hoshino. Tokai University Press. Tokyo. VII +45.5 pp. (in Japanese). 
Nakasone, Y. 1977. Crab zonation in the Yuhi River, Okinawa Island. Jap. J. Ecol., Vol. 27 (1), pp. 61-70.

Ono, Y. 1957. The interrelation among individuals of a fiddler crab, Ilyoplax pusillus De HaAN. Jap. J. Ecol., Vol. 7 (2), pp. 45-51. (in Japanese with English summary).

1959. The ecological studies on Brachyura in the estuary. Bull. Mar. Biol. Sta. Asamushi, Tohoku Univ., Vol. 9 (4), pp. 145-148.

- 1960. Interrelation among individuals of a fiddler crab, Ilyoplax pusillus De HAAN (II): The regulatory mechanism at high population density. Jap. J. Ecol., Vol. 10 (4), pp. 161-168. (in Japanese with English summary).

- 1962. On the habitat preference of ocypoid crabs in the estuary. Mem. Fac. Sci. Kyushu Univ. Ser. E (Biol.), Vol. 3, pp. 143-163.

1963. The ecological distribution of ocypoid crabs in the Yacyama Group, the Ryukyus. Rep. Comm. Foreign Sci. Res., Kyushu Univ., No. 1, pp. 49-59. (in Japanese with English summary).

1965. On the ecological distribution of ocypoid crabs in the estuary. Mem. Fac. Sci. Kyushu Univ. Ser. E (Biol.), Vol. 4, pp. 1-60.

Sakai, T. 1976. Crabs of Japan and the Adjacent Seas. Kodansha, Tokyo. 3 Volumes, 461 pp. (Japanese Text), 773 pp. (English Text), 251 pls.

Sugiyama, Y. 1961. The social structure of a sand-crab, Scopimera globosa DE HAAN, with special reference to its population. Physiol. Ecol. Japan, Vol. 10, pp. 10-17. (in Japanese with English summary).

Utashiro, T. and Horii, Y. 1965. Ecology and burrows of Scopimera globosa and Ilyoplax pusillus: Biological studies in "Lebensspuren" Part VII. Mem. Fac. Education, Niigata Univ., Takada Sch., No. 10, pp. 110-143. (in Japanese with English abstract).

Wada, K. 1976. The distribution of three species of ocypodid crabs (Crustacea: Ocypodidae) in the estuary of Waka River, mainly examined in relation to the granularity of substratum. Physiol. Ecol. Japan, Vol. 17, pp. 321-326. (in Japanese with English synopsis).

and Tsuchiya, M. 1975. Distribution of ocypodid crabs in relation to tidal level and the substratum in the Gamo Lagoon. Jap. J. Ecol., Vol. 25 (4), pp. 235-238. (in Japanese).

Yamaguch1, T., Noguchi, Y. and Ogawara, N. 1979. Studies of the courtship behavior and copulation of the sand bubbler crab, Scopimera globosa. Publ. Amakusa Mar. Biol. Lab., Vol. 5 (1), pp. $31-44$.

, Ogawara, H. and Noguchi, H. 1978. Experimental analysis of the regulatory mechanism at high population density of a bubble crab, Scopimera globosa De HAAN (Preliminary report). Benthos Research Japan, No. 15/16, pp. 18-22. (in Japanese).

- and Tanaka, M. 1974. Studies on the ecology of a sand bubbler crab, Scopimera globosa DE HAAN (Decapoda, Ocypodidae). I. Seasonal variation of population structure. Jap. J. Ecol., Vol. 24 (3), pp. 165-174. (in Japanese with English synopsis and summary). 